Purdue University Purdue e-Pubs

6-7-2008

\title{
Transport from a Volatile Meniscus Inside an Open Microtube
}

Hao Wang

Jayathi Y. Murthy

School of Mechanical Engineering, Purdue University, jmurthy@purdue.edu

S V. Garimella

Purdue University, sureshg@purdue.edu

Follow this and additional works at: http://docs.lib.purdue.edu/coolingpubs

Wang, Hao; Murthy, Jayathi Y.; and Garimella, S V., "Transport from a Volatile Meniscus Inside an Open Microtube" (2008). CTRC Research Publications. Paper 96.

http://dx.doi.org/10.1016/j.ijheatmasstransfer.2007.09.011

This document has been made available through Purdue e-Pubs, a service of the Purdue University Libraries. Please contact epubs@purdue.edu for additional information. 


\title{
Transport from a Volatile Meniscus inside an Open Microtube M $^{\S}$
}

\author{
Hao Wang, Jayathi Y. Murthy and Suresh V. Garimella" \\ Cooling Technologies Research Center \\ School of Mechanical Engineering, Purdue University \\ West Lafayette, IN 47907-2088 USA
}

\section{ABSTRACT}

A generalized model is developed which couples the evaporation at a liquid-air interface with the vapor diffusion processes in air to enable an investigation of the mass transport inside an open microtube. Tube inner diameters ranging from 100 to 1200 microns are considered. Evaporation is strongest at the meniscus junction with the tube wall due to the highest local vapor diffusion flux at this location. A temperature gradient is set up from the axis of the tube to the wall and results in Marangoni convection. The three-dimensional flow structure in the microtube is simulated with the effects of Marangoni convection, buoyancy, and the influx of fluid to the interface being included. For horizontal tubes of diameter 100 microns or larger immersed in a water bath, flow asymmetry due to buoyancy is observed. A large vortex is formed in the lower part of the tube cross-section, while a small vortex forms above. However, the primary cause of asymmetry is found to be the external thermal profile imposed on the microtube, especially when the meniscus is far from the outlet of the tube. The simulated flow patterns are found to be consistent with experimental measurements.

Keywords: diffusion, evaporation, interface, noncondensable gas, Marangoni convection, microtube, buoyancy

\footnotetext{
$\S$ Submitted for possible publication in International Journal of Heat and Mass Transfer, February 2007, and in revised form, August 2007

${ }^{\Uparrow}$ Author to whom correspondence should be addressed: 765-494-5621, sureshg@purdue.edu
} 


\section{NOMENCLATURE}

\begin{tabular}{|c|c|c|c|}
\hline$A$ & area $\left(\mathrm{m}^{2}\right)$ & $X$ & vapor molar fraction \\
\hline$D$ & mass diffusion coefficient in air $\left(\mathrm{m}^{2} / \mathrm{s}\right)$ & Greek & \\
\hline$d_{i}$ & tube inner diameter $(\mathrm{m})$ & $\beta$ & thermal expansion coefficient $(1 / \mathrm{K})$ \\
\hline$d_{o}$ & tube outer diameter $(\mathrm{m})$ & $\delta$ & thickness (m) \\
\hline$F$ & vapor mass fraction & $\theta$ & contact angle \\
\hline$h_{f g}$ & latent heat of evaporation $(\mathrm{J} / \mathrm{kg})$ & $v$ & kinematic viscosity $\left(\mathrm{m}^{2} / \mathrm{s}\right)$ \\
\hline$h$ & convection coefficient $\left(\mathrm{W} / \mathrm{m}^{2} \mathrm{~K}\right)$ & $\mu$ & dynamic viscosity $\left(\mathrm{Ns} / \mathrm{m}^{2}\right)$ \\
\hline$h_{l}$ & liquid enthalpy $(\mathrm{J} / \mathrm{kg})$ & $\rho$ & density $\left(\mathrm{kg} / \mathrm{m}^{3}\right)$ \\
\hline$k$ & thermal conductivity $(\mathrm{W} / \mathrm{m} \mathrm{K})$ & $\sigma$ & surface tension coefficient $(\mathrm{N} / \mathrm{m})$ \\
\hline$L$ & distance from tube outlet $(\mathrm{m})$ & $\hat{\sigma}$ & accommodation coefficient \\
\hline$m_{n e t}$ & mass flow rate $(\mathrm{kg} / \mathrm{s})$ & $\tau$ & shear stress $\left(\mathrm{N} / \mathrm{m}^{2}\right)$ \\
\hline$m^{\prime \prime}{ }_{n e t}$ & mass flux $\left(\mathrm{kg} / \mathrm{m}^{2} \mathrm{~s}\right)$ & Subsc & \\
\hline $\bar{M}$ & molecular weight $(\mathrm{kg} / \mathrm{kmol})$ & air & air \\
\hline$n$ & interfacial normal coordinate (m) & cell & cell element \\
\hline$N u$ & Nusselt number & $e$ & evaporation \\
\hline$p$ & pressure $\left(\mathrm{N} / \mathrm{m}^{2}\right)$ & equ & equilibrium \\
\hline $\bar{R}$ & universal gas constant $(\mathrm{J} / \mathrm{mol} \mathrm{K})$ & $f$ & face of cell element \\
\hline$r_{i}$ & tube inner radius (m) & $g$ & gas (vapor/air mixture) \\
\hline$r_{o}$ & tube outer radius $(\mathrm{m})$ & $l$ & liquid \\
\hline$R a$ & Rayleigh number & $l v$ & interface \\
\hline$s$ & interfacial tangential coordinate $(\mathrm{m})$ & out & outlet \\
\hline$S_{m}$ & mass source term $\left(\mathrm{kg} / \mathrm{m}^{3} \mathrm{~s}\right)$ & ref & reference \\
\hline$S_{e}$ & energy source term $\left(\mathrm{W} / \mathrm{m}^{3}\right)$ & sat & saturated \\
\hline $\operatorname{Pr}$ & Prandtl number & $v$ & vapor \\
\hline$T$ & temperature $(\mathrm{K})$ & $w$ & tube wall \\
\hline$V$ & velocity $(\mathrm{m} / \mathrm{s})$ & & \\
\hline
\end{tabular}




\section{INTRODUCTION}

The use of evaporating menisci in pores and grooved structures is becoming increasingly common in a number of applications including heat pipes, chemical processing equipment and microfluidic devices. In heat pipe applications, for example, the emphasis is on maximizing the rate of evaporation from the meniscus. This in turn depends on the meniscus thickness, the mixing induced by Marangoni and buoyant convection, as well as the rate of diffusion of the evaporated vapor in air near the meniscus. It is necessary to understand the details of the flow, heat and mass transfer near evaporating menisci to develop better microstructures to aid evaporation. Evaporation in an open-tube meniscus constitutes a simple canonical problem in which the most critical effects can be elucidated.

The flow field and thermal conditions in the vicinity of the meniscus have been widely studied [1-14]. A comprehensive theoretical analysis of evaporating/condensing liquid films was conducted in [2]. Vapor recoil and Marangoni convection were included. Evaporation and condensation are governed by the departure from thermodynamic equilibrium at the interface. Schmidt [3] discussed the influence of Marangoni and buoyancy effects on the flow field near an evaporating meniscus. In $[4,5,6]$, the disjoining pressure due to long-range molecular forces was considered. In these studies, the vapor domain was treated as being uniformly saturated such that diffusion in the vapor domain did not need to be considered. In contrast, Deegan et al. [7] showed that evaporation of water droplets is limited by diffusion of vapor in air. Cachile et al. [8] explained their experimental results involving freely receding evaporating droplets using the same framework. In an open microtube at room temperature, as shown in recent experiments by Buffone et al. [9,10,11], thermocapillary convection sets up a recirculation from the meniscus center towards the tube wall, contrary to previous results [12] in which the Marangoni flow was reported to flow away from the heated wall. Rice and Faghri [13] computed vapor diffusion in the air domain and found that diffusion is stronger at the wall than at the center of the meniscus, which could induce the Marangoni flows observed in [10,11]. Recent detailed experiments [14] showed an increasing asymmetry in the flow pattern near the evaporating meniscus with increasing tube diameter.

The objective of the present work is first to develop a generalized model for evaporation from a meniscus into air. Unlike previous studies accounting for only evaporation [2-5] or diffusion [7-13], the combined effects of evaporation and diffusion are modeled in present work. Furthermore, the threedimensional flow field in the microtube is simulated with a consideration of Marangoni, buoyancy, and evaporation effects. The growth in flow asymmetry with tube size found experimentally [14] is realized in the simulations as well. The effects of externally imposed temperature gradients on the tube are also considered. Since this external gradient strongly affects Marangoni convection, it is shown to have a far more profound effect on flow asymmetry than does buoyancy. 


\section{MATHEMATICAL MODEL}

\subsection{Problem Description}

A pinned meniscus located inside a capillary tube at a distance $L$ from the tube outlet is considered, as shown in Fig. 1. On one end of the tube is the liquid inlet while on the other is the outlet for vapor. The tube is in an ambient of air at room temperature. A convection heat transfer boundary condition is imposed on the outer wall of the tube

$$
-k_{w} \nabla T \cdot \vec{n}=h\left(T_{w}-T_{\text {air }}\right)
$$

in which $T_{\text {air }}$ is assumed $298 \mathrm{~K}$ and $T_{w}$ is to be calculated. The value of the convection coefficient $h$ corresponds to natural convection from a long horizontal cylinder:

$$
h=\frac{k}{d_{o}} N u
$$

with the Nusselt number $N u$ given by [15]:

$$
N u=\left(0.6+\frac{0.387 R a^{1 / 6}}{\left(1+(0.559 / \mathrm{Pr})^{9 / 16}\right)^{8 / 27}}\right)^{2} \quad, R a=\left(\mathrm{g} \beta\left|\mathrm{T}_{\mathrm{w}}-\mathrm{T}_{\text {air }}\right| \mathrm{d}_{\mathrm{o}}{ }^{3} \operatorname{Pr}\right) / v^{2}
$$

For a tube of $d_{o}=600 \mu \mathrm{m}$ and $T_{w}-T_{\text {air }}=10 \mathrm{~K}, h \approx 30 \mathrm{~W} / \mathrm{m}^{2} \mathrm{~K}$. Since $T_{w}$ varies along the axis direction (the section of the tube wall near the meniscus has the lowest temperature), $R a$ varies along the tube in the simulation. A given stagnation-pressure inlet for the liquid and a given static-pressure outlet [16] for the vapor are set at the two ends of the tube. The temperature of liquid at the inlet is assumed equal to the room temperature.

\subsection{Evaporative Mass Flow}

The path taken by the evaporated liquid is illustrated in Fig. 1. Liquid is first converted into vapor by evaporation at the meniscus. The vapor then diffuses through the vapor/air mixture in the tube, and out into the ambient. To obtain the evaporative mass flow rate under steady-state conditions, these three processes must be solved together as described below.

\subsubsection{Evaporation at the liquid-vapor interface}

For the evaporation process, the interface evaporation theory proposed by Schrage [17] yields the mass flux across the liquid-vapor interface:

$$
m_{n e t}^{\prime \prime}=\frac{2 \hat{\sigma}}{1-2 \hat{\sigma}}\left(\frac{\bar{M}}{2 \pi \bar{R}}\right)^{1 / 2}\left(\frac{p_{v_{e} e q u}\left(T_{l v}\right)}{T_{l v}^{1 / 2}}-\frac{p_{v}}{T_{v}^{1 / 2}}\right)
$$


Assuming the vapor temperature at the interface, $T_{v}$, to be equal to the interface temperature $T_{l v}$, Eq. (4) becomes

$$
m_{n e t}^{\prime \prime}=\frac{2 \hat{\sigma}}{1-2 \hat{\sigma}}\left(\frac{\bar{M}}{2 \pi \bar{R}}\right)^{1 / 2} \frac{1}{T_{l v}^{1 / 2}}\left(p_{v_{-} e q u}\left(T_{l v}\right)-p_{v}\right)
$$

Despite the suppression effects of the disjoining and capillary pressures $[6,18]$, the equilibrium vapor pressure is approximately the corresponding saturation pressure, $p_{v_{-} e q u}\left(T_{l v}\right)=p_{s a t}\left(T_{l v}\right)$, which in turn is given by

$$
p_{s a t}\left(T_{l v}\right)=p_{\text {sat_ref }} \exp \left(\frac{\bar{M} h_{f g}}{\bar{R}}\left(\frac{1}{T_{\text {sat_ref }}}-\frac{1}{T_{l v}}\right)\right)
$$

\subsubsection{Vapor transport through the tube}

Assuming a dilute mixture of vapor in air, the species equation describing the transport of vapor from the interface to the tube outlet is given as:

$$
0=-\nabla \cdot\left(\rho_{g} \vec{V} F\right)+\nabla \cdot\left(\rho_{g} D \nabla F\right)
$$

Given boundary conditions at the two ends, $F_{\text {out }}$ and $F_{l v}$, Eq. (7) can be solved in the vapor/air domain. The diffusion mass flux at the interface can be obtained from

$$
m_{\text {diff }}^{\prime \prime}=-\left.\frac{\partial F}{\partial n}\right|_{l_{v}} \rho_{g} D
$$

The vapor transport includes both diffusion and convection. Therefore [15]

$$
m_{\text {net }}^{\prime \prime}=\frac{m_{\text {diff }}^{\prime \prime}}{\left(1-F_{l v}\right)}
$$

This vapor transport is equal to the evaporated mass flux calculated by Eq. (5) due to mass conservation. Therefore,

$$
-\left.\frac{\partial F}{\partial n}\right|_{l v} \frac{\rho_{g} D}{1-F_{l v}}=\frac{2 \hat{\sigma}}{1-2 \hat{\sigma}}\left(\frac{\bar{M}}{2 \pi \bar{R}}\right)^{1 / 2} \frac{1}{T_{l v}^{1 / 2}}\left(p_{v_{-} e q u}\left(T_{l v}\right)-p_{v}\right)
$$

On the other hand, the vapor fraction at the interface is related to the local vapor pressure as

$$
F_{l v}=\frac{p_{v} \bar{M}_{v}}{p_{v} \bar{M}_{v}+\left(p-p_{v}\right) \bar{M}_{a i r}}
$$

Diffusion and evaporation are coupled by Eqs. (10) and (11) since the diffusion flux of vapor at the interface must equal the evaporative flux.

The total mass flow rate is the integral of the evaporated mass flux on the meniscus 


$$
m_{\text {net }}=\oint_{\text {meniscus }} m_{\text {net }}^{\prime \prime} d A
$$

\subsubsection{Vapor diffusion out of the tube}

$F_{l v}$ and $F_{\text {out }}$ are boundary conditions for the calculation of vapor diffusion in the vapor/air domain (Fig. 1). $\quad F_{l v}$ is obtained from $p_{v}$ at the interface using Eq. (11). The vapor fraction at the tube outlet, $F_{\text {out }}$, must be obtained by solving for the diffusion process from the tube outlet into the ambient. As shown in Fig. 1, a hemispherical domain is created at the outlet of the tube and its surface ( $r=r_{i}$ in Fig. 1) is assumed to have a uniform vapor mass fraction $F_{\text {out }}$. Assuming that the diffusion from the hemisphere surface to the ambient mainly occurs in the half space at the tube outlet as shown in Fig. 1, the diffusion process out of tube may be solved in spherical coordinates:

$$
\nabla^{2} F=0 \text { or } \frac{d}{d r}\left(r^{2} \frac{d F}{d r}\right)=0
$$

with boundary conditions

$$
\begin{aligned}
& r \rightarrow \infty, F=0 \\
& r=r_{i}, F=F_{\text {out }}
\end{aligned}
$$

The vapor fraction $F_{\text {out }}$ on the hemisphere surface $r=r_{i}$ is obtained from

$$
F_{\text {out }}=\frac{m_{\text {net }}}{2 \pi r_{i} \rho_{g} D}
$$

The mass flow rate $m_{n e t}$ is equal to the integrated mass evaporated from the interface (Eq. (12)).

In summary, three equations - Eq. (5) for the evaporation at the interface, Eq. (7) for the vapor transport in the tube and Eq. (15) for diffusion outside the tube - must be solved to obtain the three unknowns, $m_{n e t}$, $F_{\text {out }}$ and $F_{l v}$. Eq. (7) is solved using a CFD model in the vapor/air mixture domain to obtain the $F$ distribution. Then $m_{n e t}$ is obtained from Eq. (9). Eq. (5) and Eq. (15) are used to derive boundary conditions $F_{l v}$ and $F_{\text {out }}$ for the CFD model. Details of the solution loop are illustrated in Fig. 2.

\subsection{Governing Equations in Liquid Domain}

Steady, laminar, incompressible flow of a Newtonian fluid is assumed in the liquid domain. Assuming all properties to be constant except the density, the continuity, momentum and energy equations are given by:

$$
\begin{gathered}
\nabla \cdot \vec{V}=0 \\
0=-\nabla p+\nabla \cdot\left(\mu_{l} \nabla \vec{V}\right)-\rho_{l} \vec{V} \cdot \nabla \vec{V}-\left(\rho_{l}-\rho_{r e f}\right) g \vec{j}
\end{gathered}
$$




$$
0=-\rho_{l} \vec{V} \cdot \nabla\left(h_{l}\right)+\nabla \cdot\left(k_{l} \nabla T\right)
$$

Natural convection is modeled using the Boussinesq approximation in which the liquid density change with temperature in the buoyancy term is given by

$$
\rho_{l}-\rho_{\text {ref }}=\rho_{\text {ref }} \beta\left(T-T_{r e f}\right)
$$

For the vapor/air domain, the flow is again assumed to be steady, laminar and Newtonian. In addition, the ideal-gas law is also assumed to hold. Since the liquid region and the vapor/air region are assumed separated by a fixed meniscus, they are solved separately. In the solid tube wall, the conduction equation is solved:

$$
\nabla^{2} T=0
$$

Continuity of heat flux and temperature are imposed at the solid/liquid interfaces.

\subsection{Liquid-Vapor Interface}

The interfacial conditions are given below.

Mass continuity:

$$
\rho_{l} \vec{V}_{l} \cdot \vec{n}=\rho_{v} \vec{V}_{v} \cdot \vec{n}
$$

Conservation of energy:

$$
-k_{l} \nabla T \cdot \vec{n}+k_{g} \nabla T \cdot \vec{n}=h_{f g} m_{\text {net }}^{\prime \prime}
$$

Conservation of normal momentum:

$$
\dot{m}_{n e t}^{\prime \prime}\left(\vec{V}_{l}-\vec{V}_{v}\right) \cdot \vec{n}+p_{l}-p_{g}=p_{c}
$$

In Eq. (23), the first term on the left is the vapor recoil force due to the momentum of the evaporating mass, and would need to be accounted for only if there is intense evaporation [19]; it is ignored here. The third term $p_{g}$ is the atmospheric pressure. The second term $p_{l}$ is influenced by the liquid flow caused by evaporation and thermocapillary convection. Using a viscous scaling approximation, the pressure change over the tube diameter $d_{i}$ due to the flow field is given by

$$
\Delta p=\frac{V \mu}{d_{i}}
$$

On the other hand, the capillary pressure scales as:

$$
p_{c}=2 \sigma / r_{i}
$$

For the low fluid velocities expected in the current problem $(<10 \mathrm{~mm} / \mathrm{s}), p_{c}$ is found to be greater than $\Delta p$ by at least three orders of magnitude. Therefore the influence of flow on the interface shape is negligible and the curvature is almost constant [20,21]. In the simulation, the meniscus is assumed to be part of the surface of a sphere which has an assumed contact angle with the inner wall of the tube. 
Finally, ignoring the shear force exerted by the low-viscosity air, the tangential force due to the surface tension gradient must balance the shear stress on the liquid. This yields

$$
\tau_{l}=-\frac{d \sigma}{d T} \frac{\partial T}{\partial s}
$$

\section{NUMERICAL ANALYSIS}

The numerical solution is obtained using the pressure-based finite volume scheme described in $[22,23]$. The commercial software package FLUENT [24] is used. Second-order upwind differencing is used for the advection terms, while the SIMPLE algorithm is used for pressure-velocity coupling.

The grid setup is as shown in Fig. 3. Hexahedral elements are used in all domains. Only one-half of the tube domain is taken into account in view of the symmetry about the vertical center-plane $(\mathrm{x}=0)$.

To simulate the mass transport across the liquid-vapor interface, it is assumed that the mass transport occurs within the two layers of mesh cells adjacent to the interface. In the liquid layer the mass is consumed due to evaporation, as shown in Fig. 4. The mass source term imposed in these liquid cells is therefore a negative value, given by:

$$
S_{m}=-m_{\text {net }}^{\prime \prime} A_{f} / V_{\text {cell }}
$$

Here, $A_{f}$ is the interface area of the cell and $V_{\text {cell }}$ is the volume of the cell. The same amount of mass is generated in the vapor cell layer adjacent to the liquid layer to mimic evaporation. Thus, by means of source terms in the two layers, mass transfer from liquid to vapor is accomplished $[25,26]$. To simulate the cooling effect at the interface, a single layer of energy source terms is employed. The results are found to be identical when the energy source terms are imposed on either the vapor side or the liquid side. For the liquid side,

$$
S_{e}=-m_{\text {net }}^{\prime \prime} h_{f g} / V_{\text {cell }}
$$

A grid-independence study was performed using methanol as the working liquid; its properties at standard conditions are listed in Table 1. Four sets of grids were generated as summarized in Table 2; the test results are shown in Table 3. Based on these results, Mesh 2 is employed in all simulations presented in this paper.

\section{RESULTS AND DISCUSSION}

Simulations were carried out using the conditions employed in the experiments of Buffone and Sefiane [27], in which the evaporation rate on the meniscus and the tube temperature were measured. Methanol was used as the working liquid. The environment was assumed to be at a room temperature of $298 \mathrm{~K}$. The contact angle between the liquid and the tube wall was set at $15 \mathrm{deg}$. A meniscus-to-outlet 
distance $L$ of $0.48 \mathrm{~mm}$, and tube inner diameter $d_{i}$ of $600 \mu \mathrm{m}$ were considered. The tube material was borosilicate glass, with conductivity of $1.4 \mathrm{~W} / \mathrm{m}-\mathrm{K}$ as employed in [18].

Gravity as well as the external thermal profile could affect the flow and thermal fields at the meniscus. We first present results without considering these effects and subsequently discuss their influence in Sections 4.4 and 4.5.

\subsection{Overall Evaporation Rate and Cooling Effect}

The total evaporated mass flow rate from the entire meniscus, which is also the mass flow rate through the tube outlet, is computed from the simulation to be $m_{\text {net }}=1.9 \times 10^{-9} \mathrm{~kg} / \mathrm{s}$, consistent with the experimental value [27] of $2.0 \times 10^{-9} \mathrm{~kg} / \mathrm{s}$. This corresponds to an evaporative heat flow rate of $2.26 \times 10^{-3}$ $\mathrm{W}$, or a heat flux of $8.0 \times 10^{3} \mathrm{~W} / \mathrm{m}^{2}$ over the tube cross-sectional area $\pi \mathrm{r}_{\mathrm{i}}{ }^{2}$. If the meniscus is assumed to have no curvature, the vapor transport in the tube may be simplified into a 1-D problem. Combining Eqs. (8) and (9) we obtain

$$
m_{\text {net }}^{\prime \prime}=\frac{\rho_{g} D}{1-F} \frac{d F}{d z}
$$

Integrating from the meniscus $\left(F=F_{l v}\right.$ at $\left.z=0\right)$ to the tube outlet $(F \approx 0$ at $z=-L)$, we find:

$$
m_{n e t}^{\prime \prime}=-\frac{\rho_{g} D}{L} \ln \left(1-F_{l v}\right)
$$

which is the equation for Stephan's flow [15] under the combined action of diffusion and convection produced as a result of phase change at the meniscus. Using Eq. (30), $m_{\text {net }}=1.6 \times 10^{-9} \mathrm{~kg} / \mathrm{s}$ is predicted when $L=0.48 \mathrm{~mm}$, which compares well with both the full simulation and the experimental result. From Eq. (30) it is clear that $m_{n e t}$ is inversely proportional to the length of the vapor region, $L$. This occurs because a longer vapor/air region increases the diffusion resistance, and suppresses the evaporative mass flow rate.

Evaporation at the meniscus has a cooling effect on the tube wall. A maximum temperature drop of $7 \mathrm{~K}$ below room temperature is observed on the outer surface of the tube from the predicted results, as shown in Fig. 5. The IR measurements in [27] indicated a similar temperature distribution on the tube, with the lowest temperature occurring near the location of the meniscus.

\subsection{Non-uniformity of Vapor Diffusion Flux on Meniscus}

Contours of the vapor fraction of methanol in the tube are shown in Fig. 6(a). The vapor fraction decreases from $F_{l v} \approx 0.13$ at the meniscus to $F_{\text {out }} \approx 2.7 \times 10^{-8}$ at the outlet; the corresponding drop in vapor pressure is $1.1 \times 10^{4} \mathrm{~Pa}$. An important observation is that the vapor mass fraction contours in the nearwall region are denser than at the tube axis. The larger value of mass fraction gradient leads to a higher diffusion flux at the wall. The evaporation flux along the meniscus is shown in Fig. 6(b), and is greatest 
at wall. The non-uniformity of the diffusion flux on the meniscus results in stronger evaporation at the wall, and correspondingly, greater cooling. The liquid domain temperature in Fig. 6(c) and the meniscus temperature in Fig. 6(d) both indicate that the lowest interface temperature occurs at the wall.

The larger value of mass fraction gradient at the wall is due to meniscus curvature, as seen in Fig. 6(a). The distance to the tube outlet from the wall-meniscus contact line is shorter than that from the meniscus center. Furthermore, since the direction for vapor diffusion is normal to the meniscus, vapor evaporating from the meniscus near the wall tends to diffuse towards the tube axis. If the contact angle of the meniscus were $90 \mathrm{deg}$, this non-uniformity in diffusion flux would disappear.

\subsection{Marangoni and Feeding Flow}

Marangoni convection at the liquid-vapor interface drives the liquid to flow from the warm region at the tube centerline to the cool region at the wall. The meniscus temperature distribution in Fig. 6(d) induces a Marangoni vortex with the flow direction being from the meniscus center to the wall, as shown in Fig. 7(a) along the vertical center plane in the liquid domain. In the 3D view shown in Fig. 7(b), a toroidal vortex can be seen near the meniscus.

Fig. 7(b) also shows the feeding flow from the inlet which replenishes the mass lost to evaporation from the meniscus. The feeding velocity at the inlet is approximately $9 \mu \mathrm{m} / \mathrm{s}$. The flow streamlines are parallel to the tube axis until the vicinity of the meniscus is approached, after which the fluid is entrained by the vortex at the meniscus. If the Marangoni effect is turned off in the simulation, the flow field shown in Fig. 8 is obtained, and the feeding flow is more obvious. Since evaporation is strongest at the wall, the feeding flow is seen to be pulled toward the wall.

\subsection{Influence of Gravity}

Experimental data for flow near the meniscus in [27] and [14] indicate that the flow in the vertical center plane (i.e., the y-z plane) in Fig. 7 may lose symmetry about the horizontal plane. Two possible agents could cause this loss of symmetry. For sufficiently large Rayleigh numbers, buoyant convection in the liquid would act to destroy symmetry. The liquid is cooled at the meniscus due to evaporation and is warmer in the interior of the fluid, causing a recirculation in the direction shown in Fig. 9. Another agent which could destroy the top-to-bottom symmetry is the presence of an external temperature gradient, that is, a y-direction gradient on the tube outer surface. We explore both these effects below.

The buoyancy-driven flow scales as $d^{3}$ and depends strongly on tube size. In Fig. 10, a series of flow patterns with increasing tube inner diameter are shown. For the $100 \mu \mathrm{m}$ diameter tube, the gravitational influence is weak. The flow pattern is almost symmetrical about the horizontal center plane. When the tube size increases to $600 \mu \mathrm{m}$, however, asymmetry appears, with the top vortex being a little smaller than the bottom one. At the same time, the backward flow proposed in Fig. 9 is observed 
at the bottom in Fig. 10. When the tube diameter is further increased to $1200 \mu \mathrm{m}$, the gravitational influence is more significant: the bottom vortex grows larger and occupies much of the tube diameter, while the top vortex shrinks into the top corner.

The strength of the Marangoni and buoyancy flows are represented by the Marangoni and Rayleigh numbers, respectively:

$$
\begin{aligned}
& M a=\frac{d \sigma}{d T} \frac{\Delta T_{1}}{r_{i}} r_{i}^{2} \frac{1}{\mu k} \\
& R a=g \beta \Delta T_{2} d_{i}^{3} / v k
\end{aligned}
$$

Here $\Delta T_{l}$ is the temperature difference across the meniscus due to non-uniform evaporation from center to wall, and $\Delta T_{2}$ is the temperature difference between the average temperature on the meniscus and the interior bulk temperature (which is $298 \mathrm{~K}$ ). When the tube size increases, as listed in Table 4, the strength of the buoyant and Marangoni flows both increase, but the increase in buoyant flow is greater, causing the ratio $R a / M a$ to increase. From Table 4 it is also seen that the evaporation flux $\mathrm{m}_{n e t} / \pi \mathrm{r}_{\mathrm{i}}^{2}$ is inversely proportional to tube size.

The 3D flow structure for asymmetrical flow is shown in Fig. 11. A small vortex is seen at the top corner while a large vortex is noted at the bottom. Unlike the case of the symmetrical flow in Fig. 7(b), the feeding flow is first entrained into the small vortex and subsequently reaches the bottom vortex in a 3D flow pattern.

The asymmetry caused by gravity is found to be insensitive to vapor region length $L$, i.e., the distance of the meniscus from the tube outlet, as demonstrated in Fig. 12. When the meniscus is deeper inside the tube, the evaporation rate drops; the temperature difference across the meniscus $\Delta T_{1}$ and the temperature difference between the meniscus and the bulk flow $\Delta T_{2}$ also drop as a result. As listed in Table 5, although $R a$ and $M a$ both decrease, the ratio $R a / M a$ does not vary much with $L$, resulting in the similarity between the flow patterns shown in Fig. 12.

\subsection{Influence of External Temperature Profile}

Asymmetrical flow patterns were observed in experiments by Chamarthy et al. [14] and Dhavaleswarapu et al. [28, 29] in which the fluorinated ethylene propylene (FEP) tube was immersed in a water bath at room temperature. The contact angle between the liquid and the tube wall was 50 deg. In this section, computations performed for the configuration in [14] are presented.

The experimental and simulation results are shown together in Fig. 13(a)-(c). Fig. 13(b) shows the simulation results when both buoyancy and Marangoni convection are taken into account. As expected, the presence of buoyancy causes an increase in asymmetry with tube size, and this effect is captured by the simulation. However, the extent of asymmetry is not as great as in the experimental results. On the 
other hand, if the tube outer surface has a temperature profile which increases linearly in the positive y direction, i.e., temperature drops from top to bottom, much stronger asymmetry, similar to that in the experiments, is computed, as shown in Fig. 13 (c) along the vertical center plane. The reason is that the imposed temperature profile changes the temperature distribution on the meniscus, making the top part warmer and bottom part cooler, such that Marangoni flow towards the bottom is stronger. For the case shown in Fig. 13 (c), a temperature gradient of $0.03 \mathrm{~K} / \mathrm{mm}$ was imposed on the outer surface. For an outer tube diameter of $800 \mu \mathrm{m}$ (inner diameter $400 \mu \mathrm{m}$ ), this gradient implies a temperature difference of $0.024 \mathrm{~K}$ between the tube top and bottom. Even this mild external temperature profile induces a much stronger asymmetry than buoyancy. Mild external temperature variations could arise from temperature non-uniformities in the water bath; however, such highly resolved temperature measurements are very difficult to obtain, and were not available from the experiments.

Unlike the asymmetry induced by buoyancy alone (Section 4.4), the asymmetry due to the external temperature profile is quite sensitive to the length of the vapor region, $L$. Fig. 14 shows a series of flow patterns in a $400 \mu \mathrm{m}$ tube for increasing $L$. The flow pattern is clearly more sensitive to the external temperature profile for longer L. When $L$ is small, the evaporation rate is high and the induced temperature gradient along meniscus is large. As a result, the flow pattern is more strongly influenced by the meniscus. When the meniscus is deep inside the tube, the temperature gradient along the meniscus due to evaporation is small and it is the external temperature profile that determines the flow pattern. It is speculated that the asymmetry in the experimental results shown in Fig. 13(a) is primarily due to mild temperature non-uniformities in the water bath surrounding the tube. Further controlled experiments are needed to validate the strong influence of even small variations in external temperature distribution on the flow patterns.

\section{CONCLUSIONS}

Heat and mass transfer at the meniscus of a volatile liquid evaporating inside a microtube are numerically investigated. Convection due to Marangoni effects and buoyancy in the liquid region, evaporation at the meniscus, transport of vapor in the tube, and diffusion of vapor from the tube outlet into the ambient are solved together. Evaporation is found to be stronger at the junction of the meniscus and the tube wall than at the meniscus center due to the higher diffusion flux at the wall. The resulting temperature gradient from the meniscus center to the wall brings about Marangoni flow directed from the center of the tube toward the wall.

The existence of both gravity and externally imposed temperature gradients results in asymmetric flow patterns in the liquid. Though gravity has a discernible effect for large-diameter tubes, its influence at small diameters (approximately $100 \mu \mathrm{m}$ or less) is found to be negligible. When the tube size 
increases, the vortex at the bottom grows larger while the one at the top shrinks. Mild external temperature gradients of the order of $0.01 \mathrm{~K} / \mathrm{mm}$ are found to cause significant asymmetry in the observed flow pattern when the meniscus is several centimeters away from the tube outlet. These external gradients are most likely the cause of observed flow asymmetries in experimental data.

\section{Acknowledgement}

The authors acknowledge financial support for this work from members of the Cooling Technologies Research Center (www.ecn.purdue.edu/CTRC), a National Science Foundation Industry/University Cooperative Research Center at Purdue University.

\section{REFERENCES}

[1] P. Sharath, C. Rao, M.M. Rahman, Numerical simulation of steady-state conjugate heat transfer in a circular microtube inside a rectangular substrate, Numerical Heat Transfer; Part A: Applications 49(2006) 635-654.

[2] J.P. Burelbach, S.G. Bankoff, S.H. Davis, Nonlinear stability of evaporating/condensing liquid film, Journal of Fluid Mechanics 195 (1988) 463-494.

[3] G.R. Schmidt, Thermocapillary flow about an evaporating meniscus, AIAA $27^{\text {th }}$ Thermophysics Conference, Nashville, TN, USA, 1992.

[4] B.V. Deryagin, S.V. Nerpin, N.V. Churayev, Effect of film heat transfer upon evaporation of liquids from capillaries, Bull. R. I. L. E. M. 29 (1965) 93-98.

[5] P.C. Stephan, C.A. Busse, Analysis of the heat transfer coefficient of grooved heat pipe evaporator walls, International Journal of Heat and Mass Transfer 35 (1992) 383-391.

[6] H. Wang, S.V. Garimella, J.Y. Murthy, Characteristics of an evaporating thin film in a microchannel, International Journal of Heat and Mass Transfer 50 (2007) 3933-3942.

[7] R.D. Deegan, O. Bakajin, T.F. Dupont, G. Huber, S.R. Nagel, T.A. Witten, Capillary flow as the cause of ring stains from dried liquid drops, Nature 389 (1997) 827-829.

[8] M. Cachile, O. Benichou, C. Poulard, A.M. Cazabat, Evaporating droplets, Langmuir 18 (2002) 8070-8078.

[9] C. Buffone, K. Sefiane, IR measurements of interfacial temperature during phase change in a confined environment, Experimental Thermal and Fluid Science 29 (2004) 65-74.

[10] C. Buffone, K. Sefiane, J.R.E. Christy, Experimental investigation of the hydrodynamics and stability of an evaporating wetting film placed in a temperature gradient, Applied Thermal Engineering 24 (2004) 1157-1170.

[11] C. Buffone, K. Sefiane, J.R.E. Christy, Experimental investigation of self-induced thermocapillary convection for an evaporating meniscus in capillary tube using micro-particle image velocimetry, Physics of Fluids 17 (2005) 052104.

[12] S.-K., Wee, Microscale observables for heat and mass transport, Ph.D. Thesis, Texas A\&M University, 2004.

[13] J. Rice, A. Faghri, A new computational method to track a liquid/vapor interface with mass transfer, demonstrated on the concentration driven evaporation from a capillary tube, and the Marangoni effect, ASME International Mechanical Engineering Congress and Exposition 2005, \#81433.

[14] P. Chamarthy, H.K. Dhavaleswarapu, S.V. Garimella, J.Y. Murthy, S.T. Wereley, Visualization of convection patterns near an evaporating meniscus using $\mu$ PIV, $12^{\text {th }}$ international Symposium on Flow Visualization, Germany, 2006; also Experiments in Fluids (in press).

[15] Y.A. Çengel, Heat Transfer: A Practical Approach, WCB/McGraw-Hill, 1998.

[16] S.R. Mathur, J.Y. Murthy, Pressure boundary conditions for incompressible flow using unstructured meshes, Numerical Heat Transfer B 32 (2) (1997) 283-298.

[17] R.W. Schrage, A Theoretical Study of Interface Mass Transfer, New York: Columbia University Press, 1953.

[18] A. Faghri, Heat Pipe Science and Technology, Washington, DC: Taylor \& Francis, 1995.

[19] V.S. Nikolayev, D.A. Beysens, Boiling crisis and non-equilibrium drying transition, Europhysics Letters 47 (3) (1999) 345-351. 
[20] L.W. Swanson, G.C. Herdt, Model of the evaporating meniscus in a capillary tube, Journal of Heat transfer 114 (1992) 434-441.

[21] D. Welter, The effect of evaporation on the dynamic capillary pressure in heat pipes, Master's Thesis, University of Dayton, Ohio, 1991.

[22] S.R. Mathur, J.Y. Murthy, A pressure-based method for unstructured meshes, Numerical Heat Transfer 31 (2) (1997) 195-216.

[23] J.Y. Murthy, S.R. Mathur, A conservative numerical scheme for the energy equation, Journal of Heat Transfer 120 (1998) 1081-1085.

[24] Fluent Inc., Fluent 6.2 User's Guide, 2004.

[25] D. Juric, G. Tryggvason, Computation of boiling flows, International Journal of Multiphase Flow 24 (1998) 387-410.

[26] U. Vadakkan, J. Y. Murthy, S.V. Garimella, Transient analysis of flat heat pipes, Proceedings of HT2003, 47349.

[27] C. Buffone, K. Sefiane, Investigation thermocapillary convection in pores and its role in heat and mass transfer enhancement, International Journal of Multiphase Flow 30 (2004) 1071-1091.

[28] H.K. Dhavaleswarapu, P. Chamarthy, S.V. Garimella, J.Y. Murthy, S.T. Wereley, Experimental investigation of thermocapillary convection near an evaporating meniscus, IMECE2006-13901, 2006.

[29] H.K. Dhavaleswarapu, P. Chamarthy, S.V. Garimella, J.Y. Murthy, Experimental investigation of steady buoyant-thermocapillary convection near an evaporating meniscus, Physics of Fluids 19 (2007) 082103. 


\section{LIST OF TABLES}

Table 1. Fluid properties ( $298 \mathrm{~K}, 1 \mathrm{~atm})$.

Table 2. Different meshes used in the mesh-independence study.

Table 3. Mesh-independence results.

Table 4. Variation of Rayleigh and Marangoni numbers and evaporation flux with tube size.

Table 5. Variation of Rayleigh and Marangoni numbers and evaporation flux with distance of meniscus from tube outlet, $L(\mathrm{di}=600 \mu \mathrm{m})$.

\section{LIST OF FIGURES}

Fig. 1. Schematic diagram of evaporating meniscus in a microtube.

Fig. 2. Iteration loop for mass flow calculation.

Fig. 3. Mesh setup as an isometric view on the left, and through the vertical center plane on the right.

Fig. 4. Source terms imposed in interface cells.

Fig. 5. Axial temperature variation along the outer surface of the tube.

Fig. 6. Evaporating meniscus in tube $(\mathrm{L}=0.48 \mathrm{~mm}, d i=600 \mu \mathrm{m})$ : (a) vapor mass fraction contours, (b) evaporated mass flux along meniscus from wall to meniscus center, (c) temperature contours in liquid $(\mathrm{K})$, and $(\mathrm{d})$ temperature contours on the meniscus $(\mathrm{K})$.

Fig. 7. Liquid flow field due to Marangoni convection and feeding flow (under zero gravity): (a) velocity vectors in vertical center plane, and (b) 3D path lines in liquid domain.

Fig. 8. Feeding flow without Marangoni convection.

Fig. 9. Gravity-induced buoyant flow.

Fig. 10. Variation of flow patterns along the vertical center plane for tube diameters $d i$ of: (a) $100 \mu \mathrm{m}$, (b) $600 \mu \mathrm{m}$, and (c) $1200 \mu \mathrm{m}$.

Fig. 11. Asymmetrical vortex induced by gravity $(\mathrm{di}=1200 \mu \mathrm{m})$ : $3 \mathrm{D}$ flow structure.

Fig. 12. Insensitivity to length $\mathrm{L}$ of the asymmetrical vortex flow pattern induced by gravity.

Fig. 13. Comparison between experimental and simulation results: (a) experimental results in [14] (L is on the order of $\mathrm{cm}$ ), (b) simulation results in the presence of gravity, $L=20 \mathrm{~mm}$, and (c) simulation results in the presence of gravity and an external temperature profile.

Fig. 14. Variation of flow pattern with meniscus distance from the outlet, $L$, under an imposed external temperature profile of $0.03 \mathrm{~K} / \mathrm{mm}$. 
Table 1. Fluid properties (298 K, $1 \mathrm{~atm})$.

\begin{tabular}{|c|c|c|}
\hline Fluid & Methanol & Air \\
\hline $\bar{M}(\mathrm{~kg} / \mathrm{kmol})$ & 32.04 & 28.97 \\
\hline$\rho\left(\mathrm{kg} / \mathrm{m}^{3}\right)$ & 786 & 1.225 \\
\hline$k(\mathrm{~W} / \mathrm{m}-\mathrm{K})$ & 0.3489 & 0.0242 \\
\hline$\mu(\mathrm{kg} / \mathrm{m}-\mathrm{s})$ & $8.56 \times 10^{-4}$ & $1.78 \times 10^{-5}$ \\
\hline$C_{p}(\mathrm{~J} / \mathrm{kg}-\mathrm{K})$ & 2534 & 1006 \\
\hline$h_{f g}(\mathrm{~kJ} / \mathrm{kg})$ & 1188.9 & - \\
\hline$d \sigma / d T(\mathrm{~N} / \mathrm{m}-\mathrm{K})$ & $8.0 \times 10^{-5}$ & - \\
\hline$\beta(1 / \mathrm{K})$ & $1.2 \times 10^{-4}$ & - \\
\hline$D\left(\mathrm{~m}^{2} / \mathrm{s}\right)$ & $1.6 \times 10^{-5}$ & - \\
\hline
\end{tabular}


Table 2. Different meshes used in the mesh-independence study.

\begin{tabular}{|c|c|c|c|c|}
\hline & Mesh 1 & Mesh 2 & Mesh 3 & Mesh 4 \\
\hline Faces on meniscus & 1,415 & 1,178 & 503 & 290 \\
\hline Cells in liquid (Hex) & 157,410 & 75,284 & 34,752 & 23,680 \\
\hline Cells in vapor (Hex) & 118,800 & 38,940 & 32,580 & 12,800 \\
\hline Cells in solid wall (Hex) & 78,120 & 36,960 & 29,760 & 20,520 \\
\hline
\end{tabular}


Table 3. Mesh-independence results.

\begin{tabular}{|c|c|c|c|c|}
\hline & Mesh 1 & Mesh 2 & Mesh 3 & Mesh 4 \\
\hline Minimum Temperature (K) & 289.90 & 289.86 & 289.77 & 289.40 \\
\hline Deviation from Mesh 1 & - & $0.014 \%$ & $0.045 \%$ & $0.172 \%$ \\
\hline Mass flow rate $\left(10^{-10} \mathrm{~kg} / \mathrm{s}\right)$ & 9.42 & 9.53 & 9.55 & 10.01 \\
\hline Deviation from Mesh 1 & - & $1.17 \%$ & $1.38 \%$ & $6.26 \%$ \\
\hline
\end{tabular}


Table 4. Variation of Rayleigh and Marangoni numbers and evaporation flux with tube size $(L=0.48$ $\mathrm{mm}$ ).

\begin{tabular}{|c|c|c|c|c|}
\hline$d_{i}(\mu \mathrm{m})$ & $R a$ & $M a$ & $R a / M a$ & $\mathrm{~m}_{\text {net }} / \pi \mathrm{r}_{\mathrm{i}}^{2}\left(\mathrm{~kg} / \mathrm{sm}^{2}\right)$ \\
\hline 100 & $2.57 \times 10^{-9}$ & $8.04 \times 10^{-6}$ & $3.20 \times 10^{-4}$ & $6.1 \times 10^{-3}$ \\
\hline 600 & $6.62 \times 10^{-7}$ & $1.13 \times 10^{-4}$ & $5.83 \times 10^{-3}$ & $3.3 \times 10^{-3}$ \\
\hline 1200 & $6.32 \times 10^{-5}$ & $7.17 \times 10^{-4}$ & $8.82 \times 10^{-2}$ & $3.0 \times 10^{-4}$ \\
\hline
\end{tabular}


Table 5. Variation of Rayleigh and Marangoni numbers and evaporation flux with distance of meniscus from tube outlet, $L\left(d_{i}=600 \mu \mathrm{m}\right)$.

\begin{tabular}{|c|c|c|c|c|}
\hline$L(\mathrm{~mm})$ & $R a$ & $M a$ & $R a / M a$ & $\mathrm{~m}_{\text {net }} / \pi \mathrm{r}_{\mathrm{i}}{ }^{2}\left(\mathrm{~kg} / \mathrm{sm}^{2}\right)$ \\
\hline 0.48 & $6.62 \times 10^{-7}$ & $1.13 \times 10^{-4}$ & $5.83 \times 10^{-3}$ & $3.3 \times 10^{-3}$ \\
\hline 3.00 & $1.86 \times 10^{-7}$ & $1.97 \times 10^{-5}$ & $9.47 \times 10^{-3}$ & $7.6 \times 10^{-4}$ \\
\hline 20.00 & $4.66 \times 10^{-8}$ & $3.96 \times 10^{-6}$ & $1.18 \times 10^{-2}$ & $2.1 \times 10^{-4}$ \\
\hline
\end{tabular}




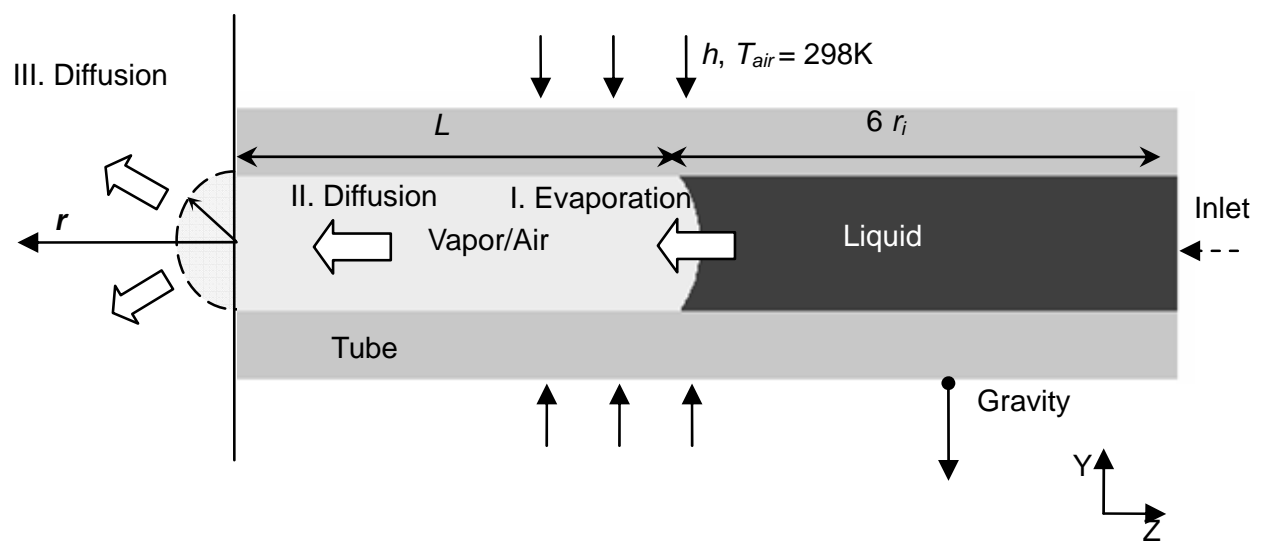

Fig. 1. Schematic diagram of evaporating meniscus in a microtube. 


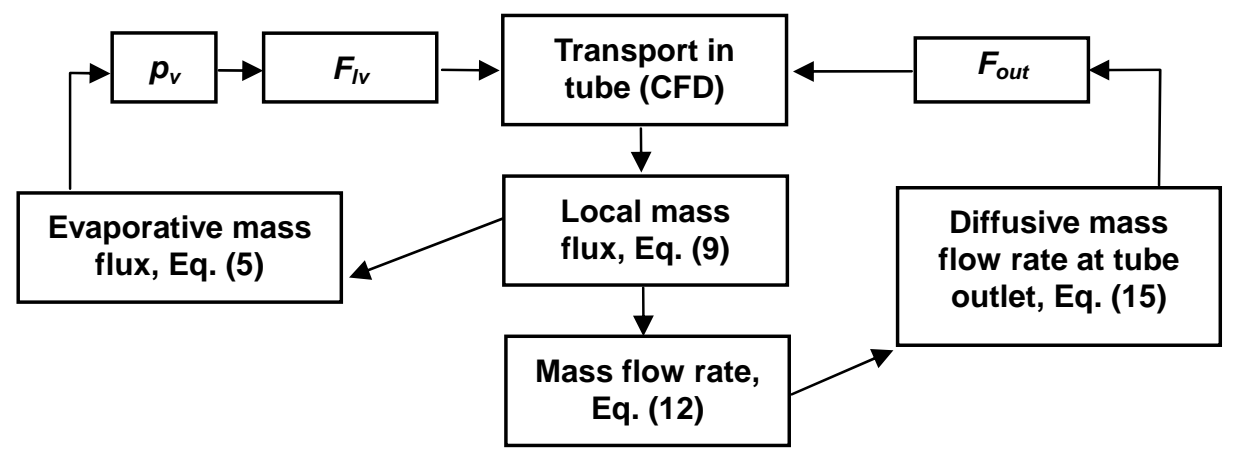

Fig. 2. Iteration loop for mass flow calculation. 


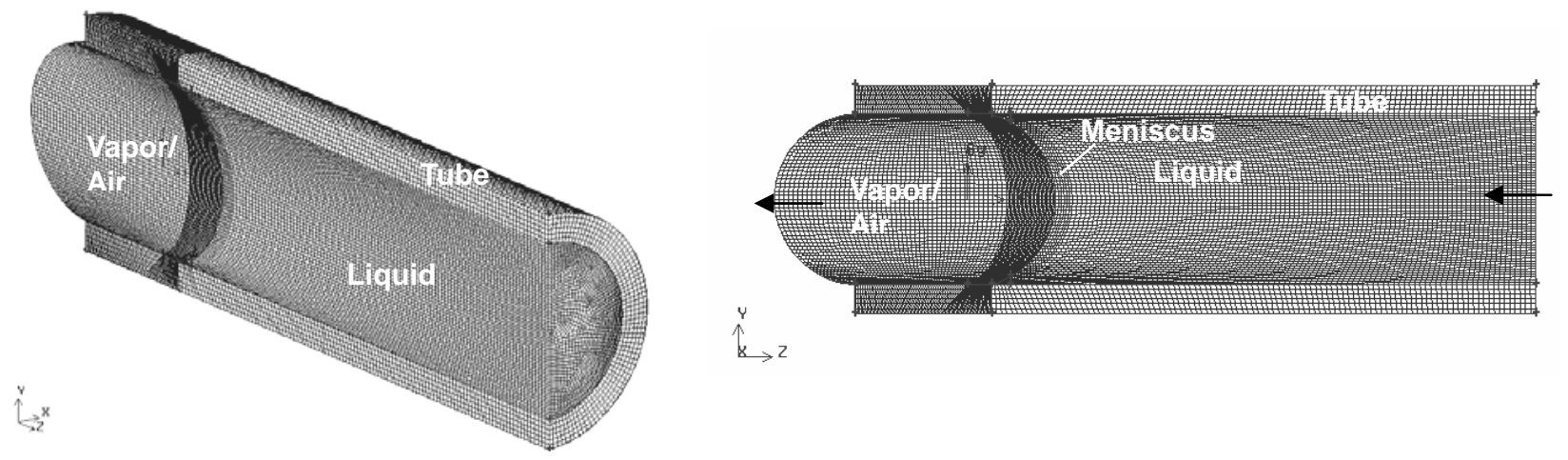

Fig. 3. Mesh setup as an isometric view on the left, and through the vertical center plane on the right. 


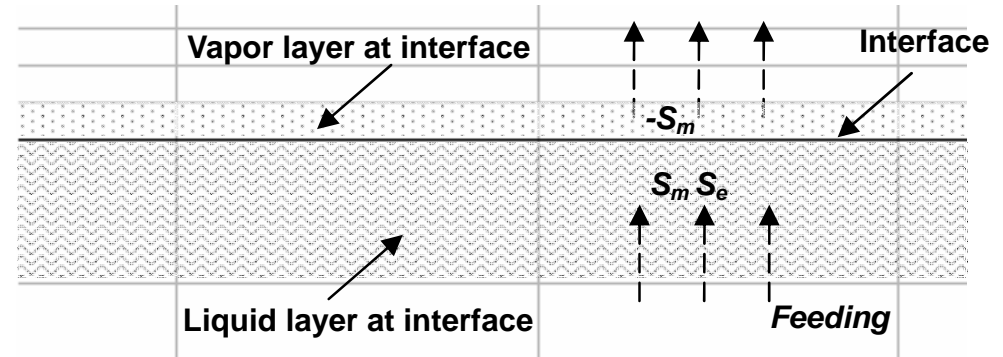

Fig. 4. Source terms imposed in interface cells. 


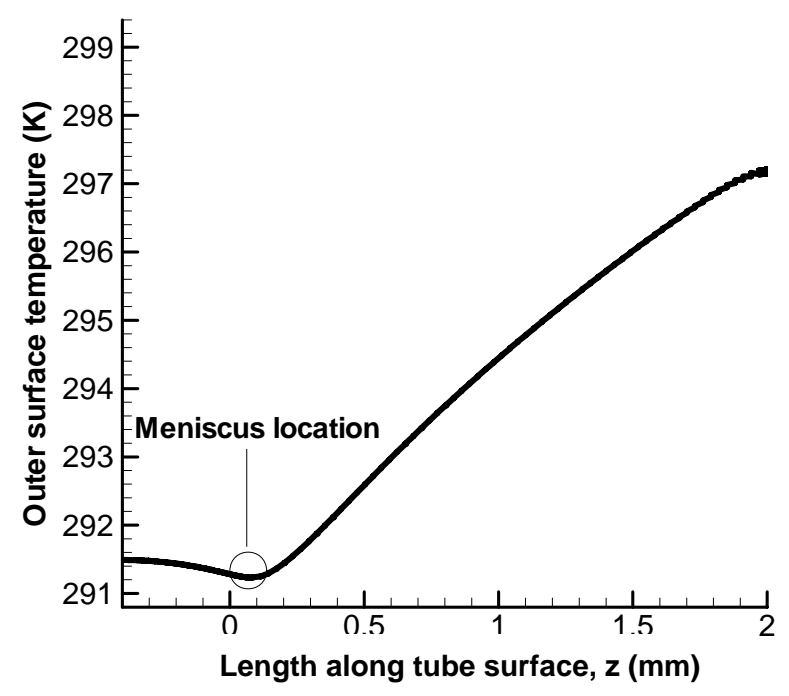

Fig. 5. Axial temperature variation along the outer surface of the tube. 


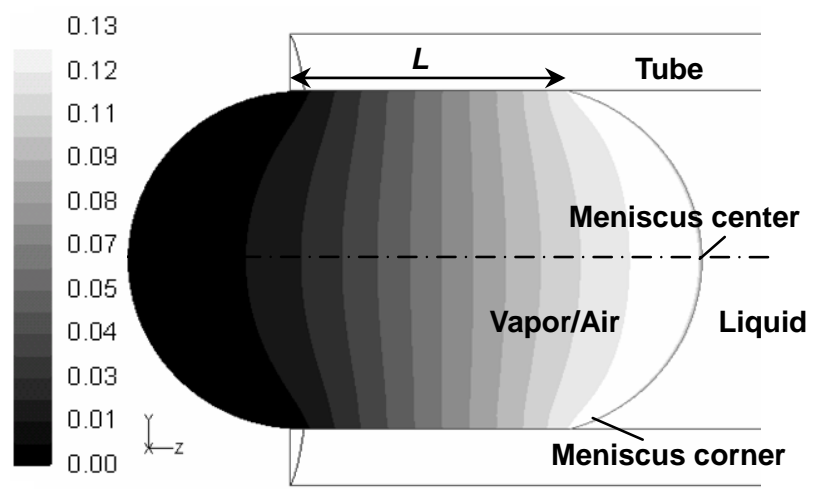

(a)

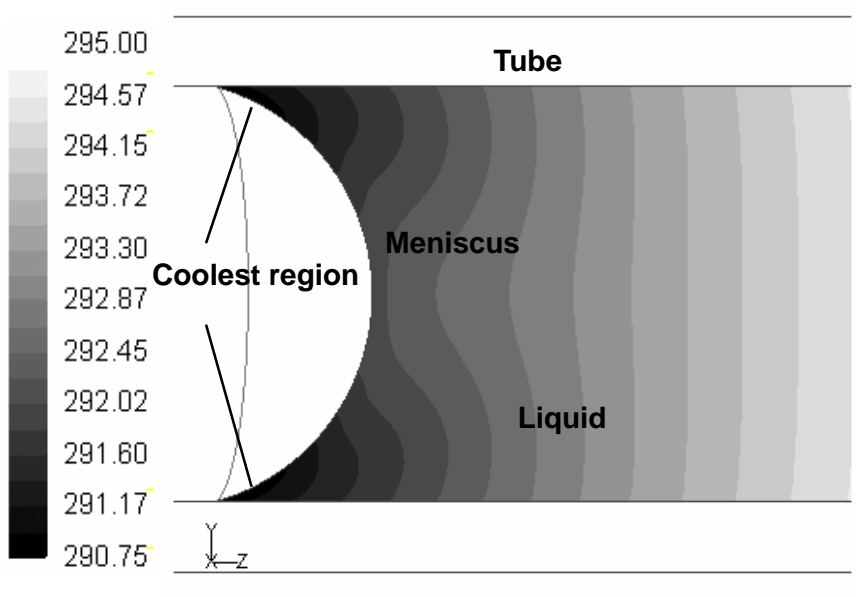

(c)

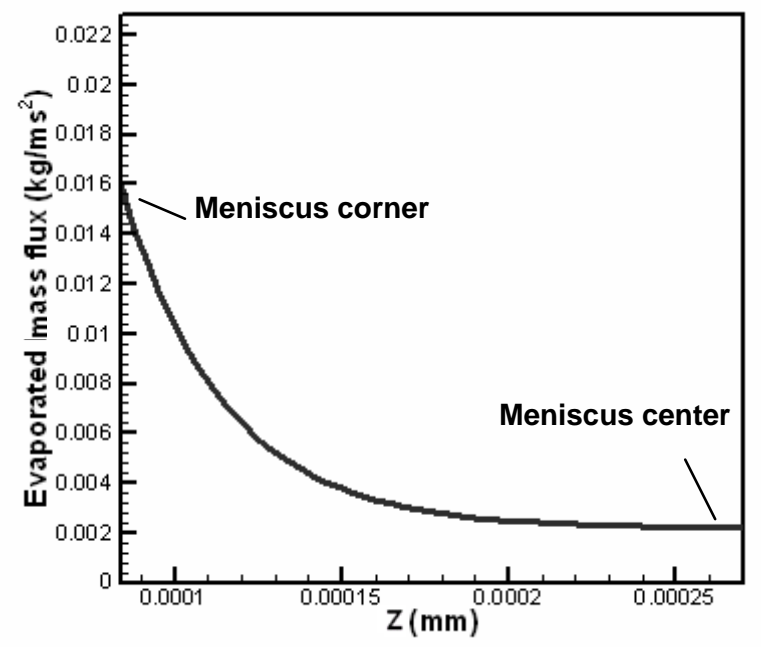

(b)

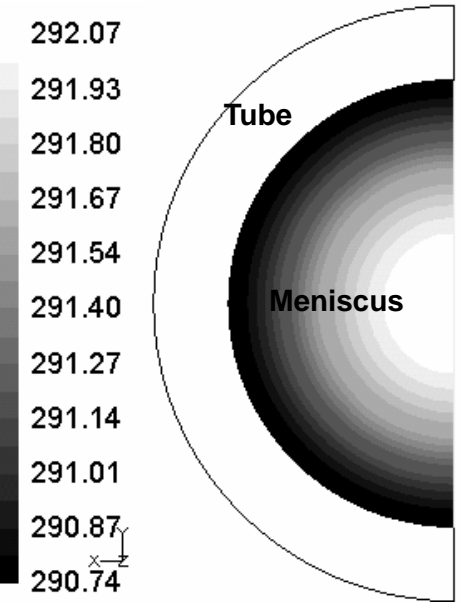

(d)

Fig. 6. Evaporating meniscus in tube $\left(L=0.48 \mathrm{~mm}, d_{i}=600 \mu \mathrm{m}\right)$ : (a) vapor mass fraction contours, (b) evaporated mass flux along meniscus from wall to meniscus center, (c) temperature contours in liquid $(\mathrm{K})$, and $(\mathrm{d})$ temperature contours on the meniscus $(\mathrm{K})$. 


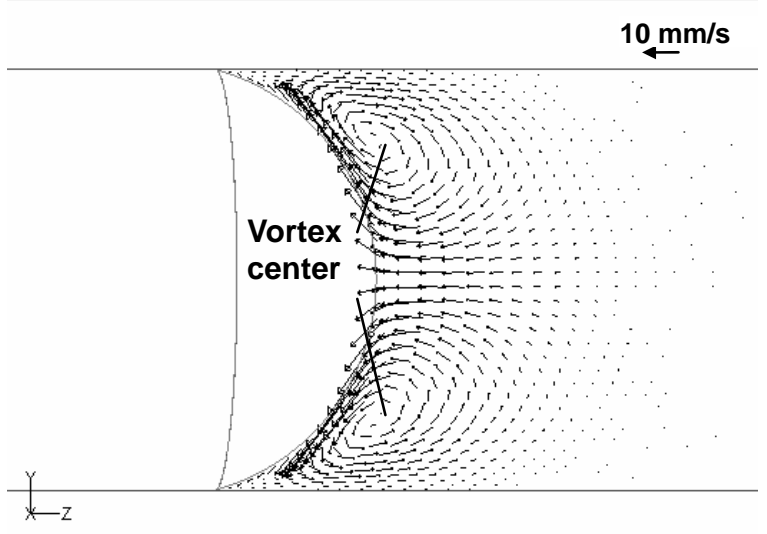

(a)

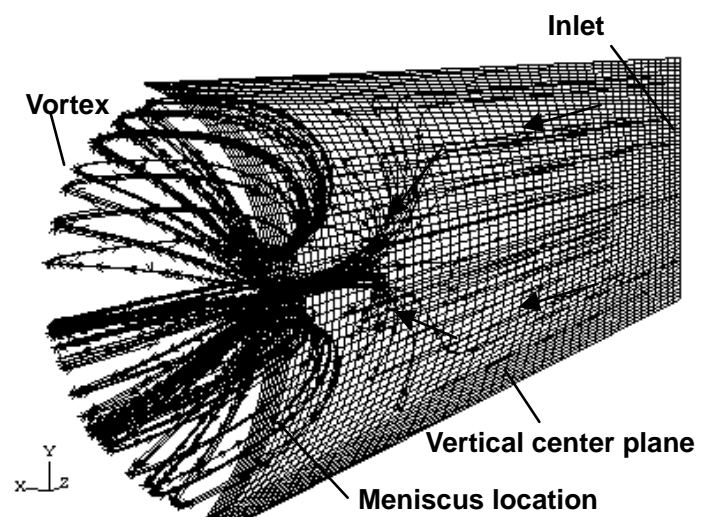

(b)

Fig. 7. Liquid flow field due to Marangoni convection and feeding flow (under zero gravity): (a) velocity vectors in vertical center plane, and (b) 3D path lines in liquid domain. 


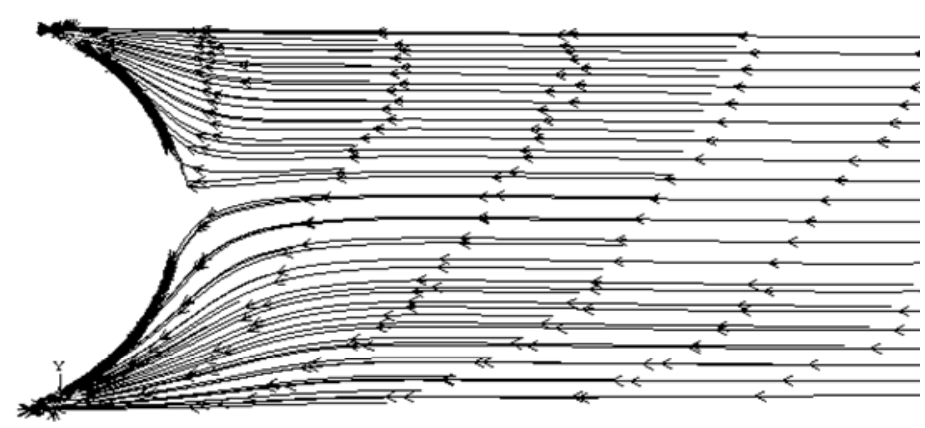

Fig. 8. Feeding flow without Marangoni convection. 


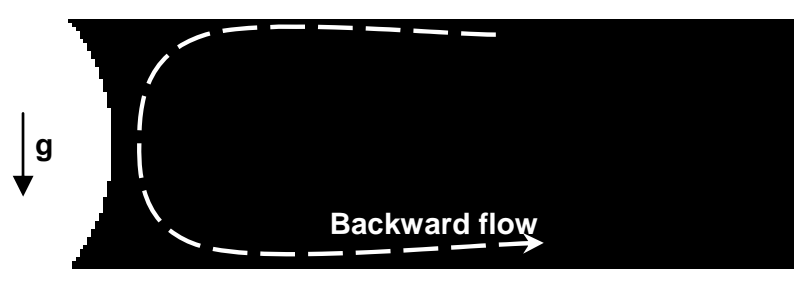

Fig. 9. Gravity-induced buoyant flow in the vertical center plane of the liquid. 


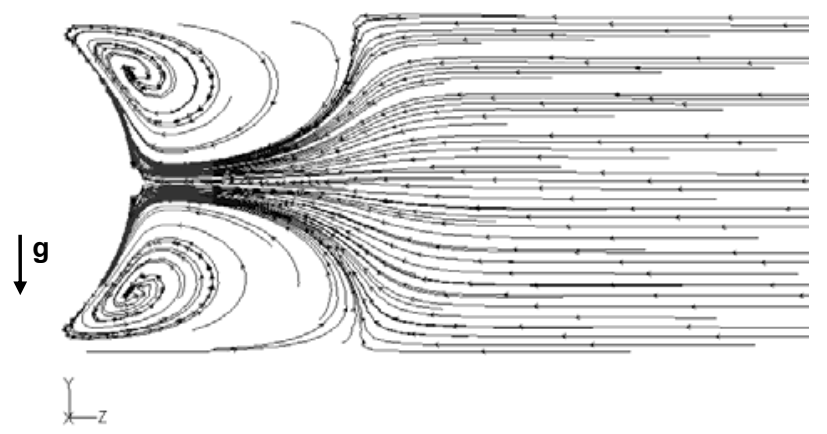

(a)

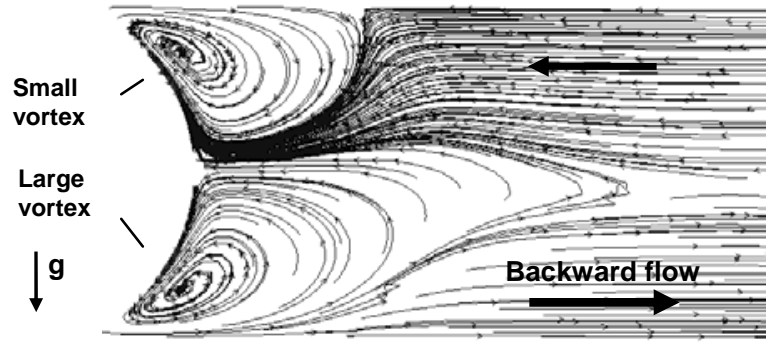

(b)

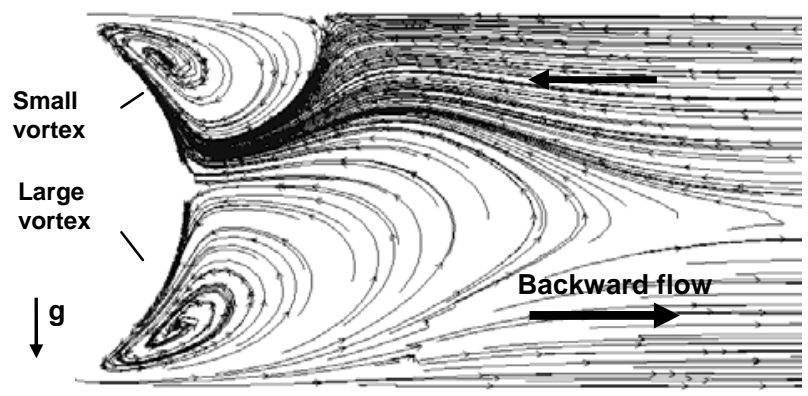

(c)

Fig. 10. Variation of flow patterns along the vertical center plane for tube diameters $d_{i}$ of: (a) 100 $\mu \mathrm{m}$, (b) $600 \mu \mathrm{m}$, and (c) $1200 \mu \mathrm{m}$. 


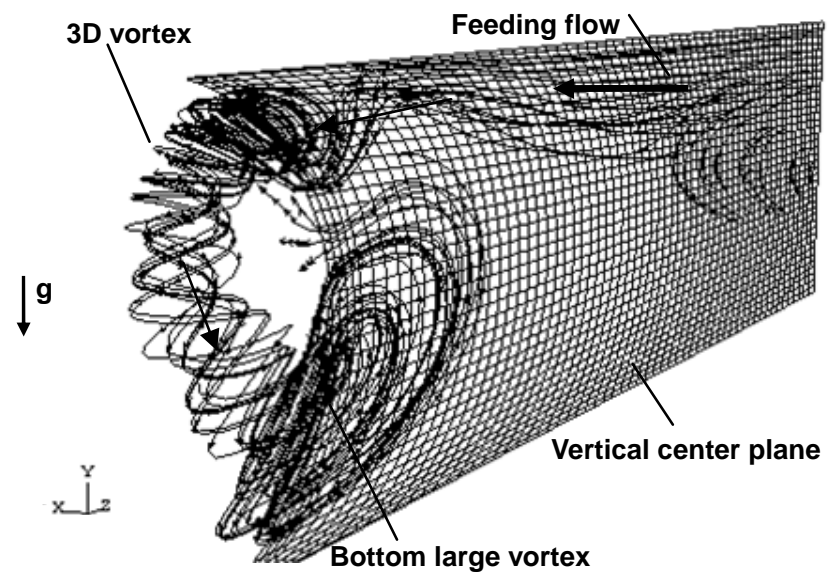

Fig. 11. Asymmetrical vortex induced by gravity $\left(d_{i}=1200 \mu \mathrm{m}\right)$ : 3D flow structure. 

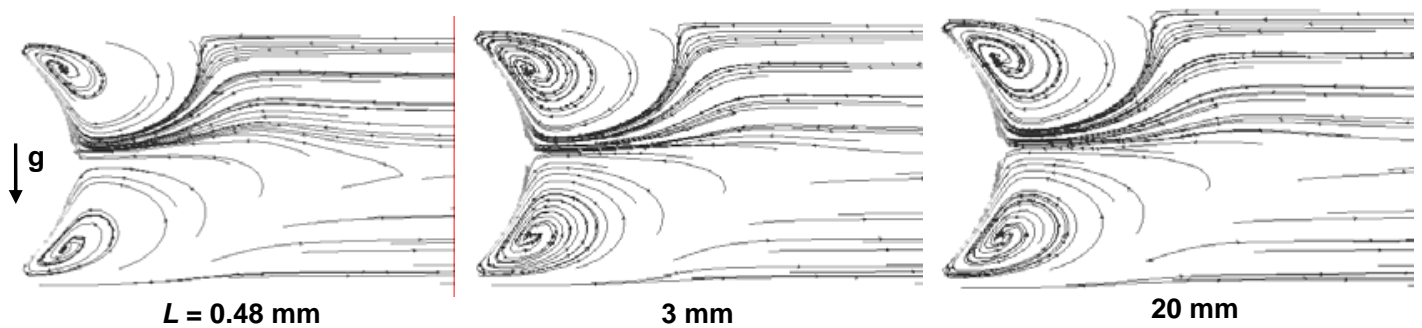

Fig. 12. Insensitivity to length $\mathrm{L}$ of the asymmetrical vortex flow pattern induced by gravity. 


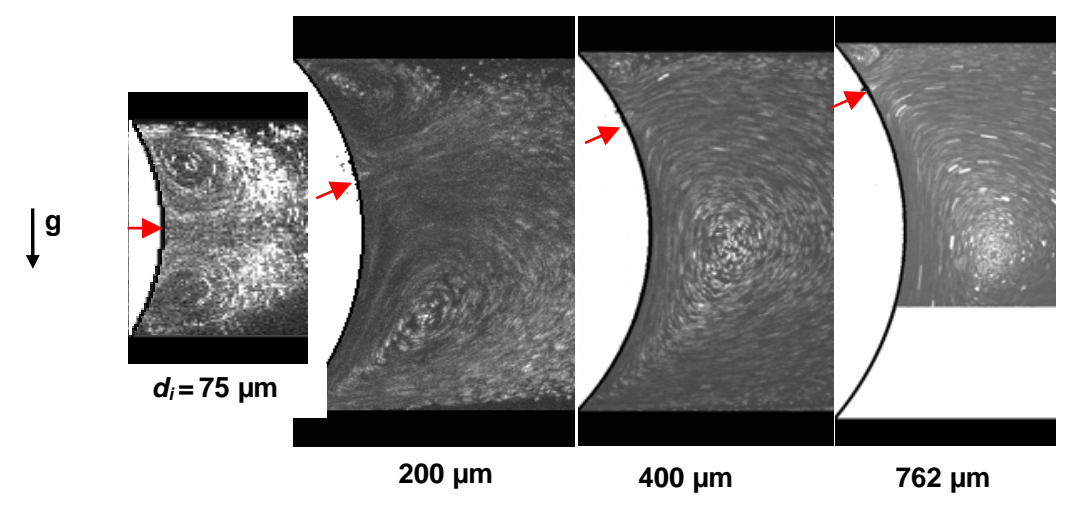

(a)

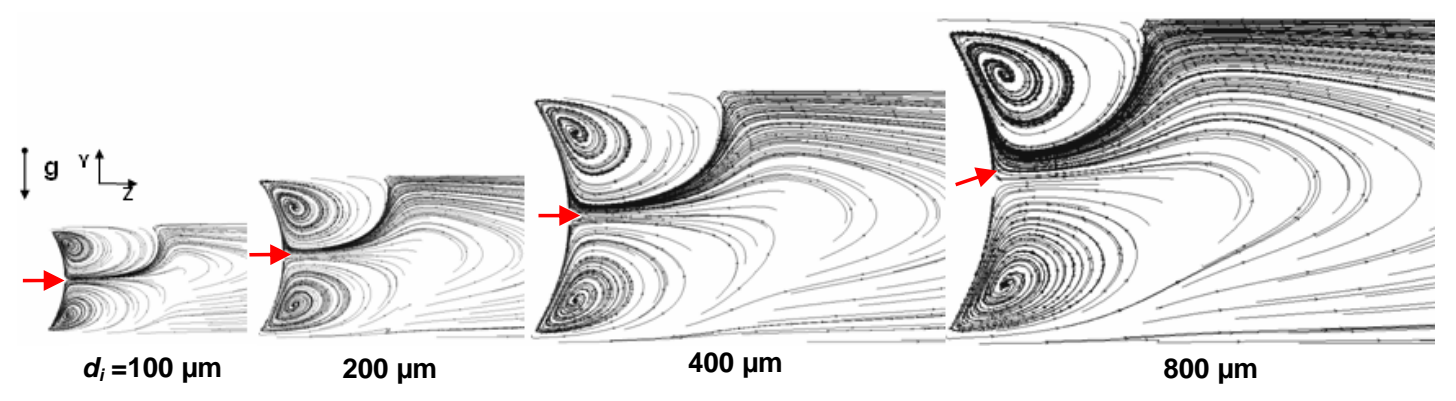

(b)

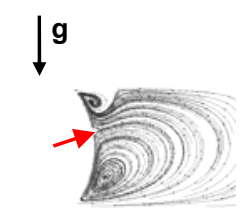

$d_{i}=100 \mu \mathrm{m}$

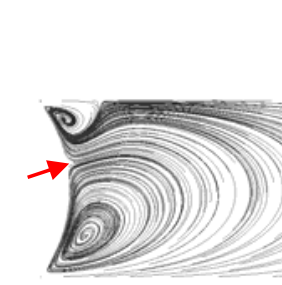

$200 \mu \mathrm{m}$

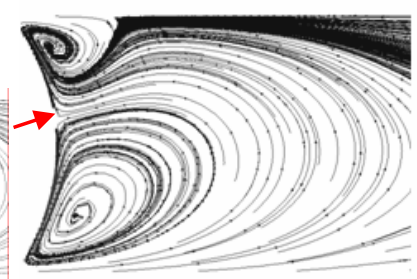

$400 \mu \mathrm{m}$

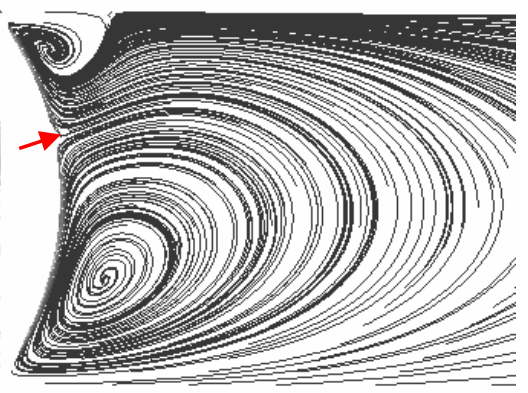

$800 \mu \mathrm{m}$

(c)

Fig. 13. Comparison between experimental and simulation results: (a) experimental results in [14] ( $L$ is on the order of $\mathrm{cm}$ ), (b) simulation results in the presence of gravity, $L=20 \mathrm{~mm}$, and (c) simulation results in the presence of gravity and an external temperature profile, $L=20 \mathrm{~mm}$. 


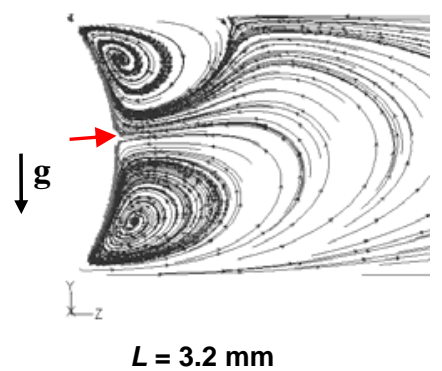

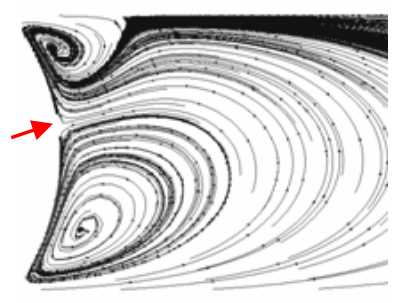

$20.0 \mathrm{~mm}$

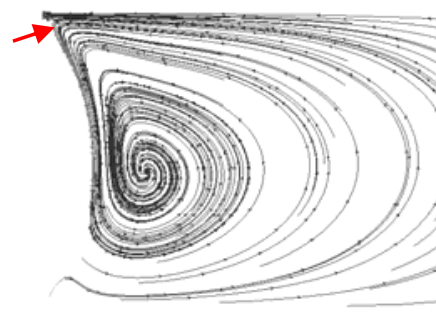

$60.0 \mathrm{~mm}$

Fig. 14. Variation of flow pattern with meniscus distance from the outlet, $L$, under an imposed external temperature profile of $0.03 \mathrm{~K} / \mathrm{mm}$. 